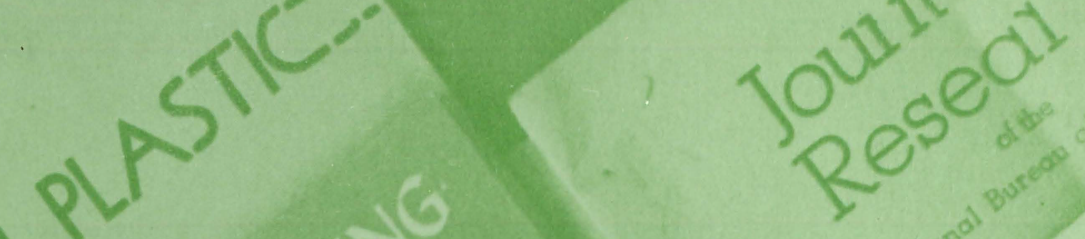

\title{
THE UNIVERSITY OF MISSOURI
}

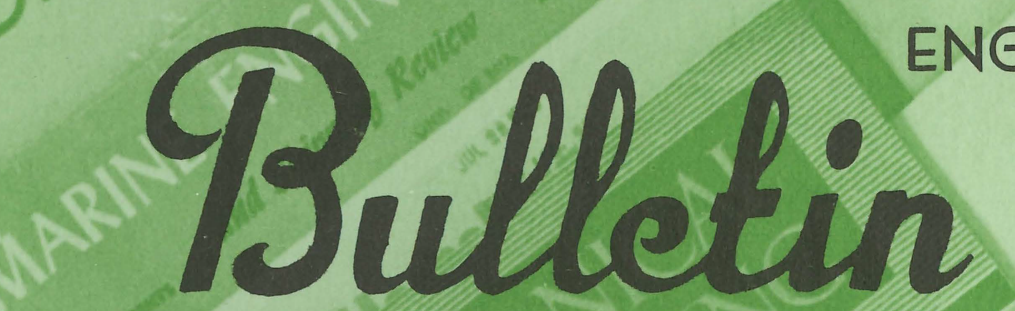

Engineering Experiment Station

Columbia, Missouri

THREE AND FOUR COIL SYSTEMS

$$
\begin{aligned}
& \text { FOR HOMOGENEOUS } \\
& \text { MAGNETIC FIELDS }
\end{aligned}
$$

3 Research Assistant, Physics Department University of Maryland

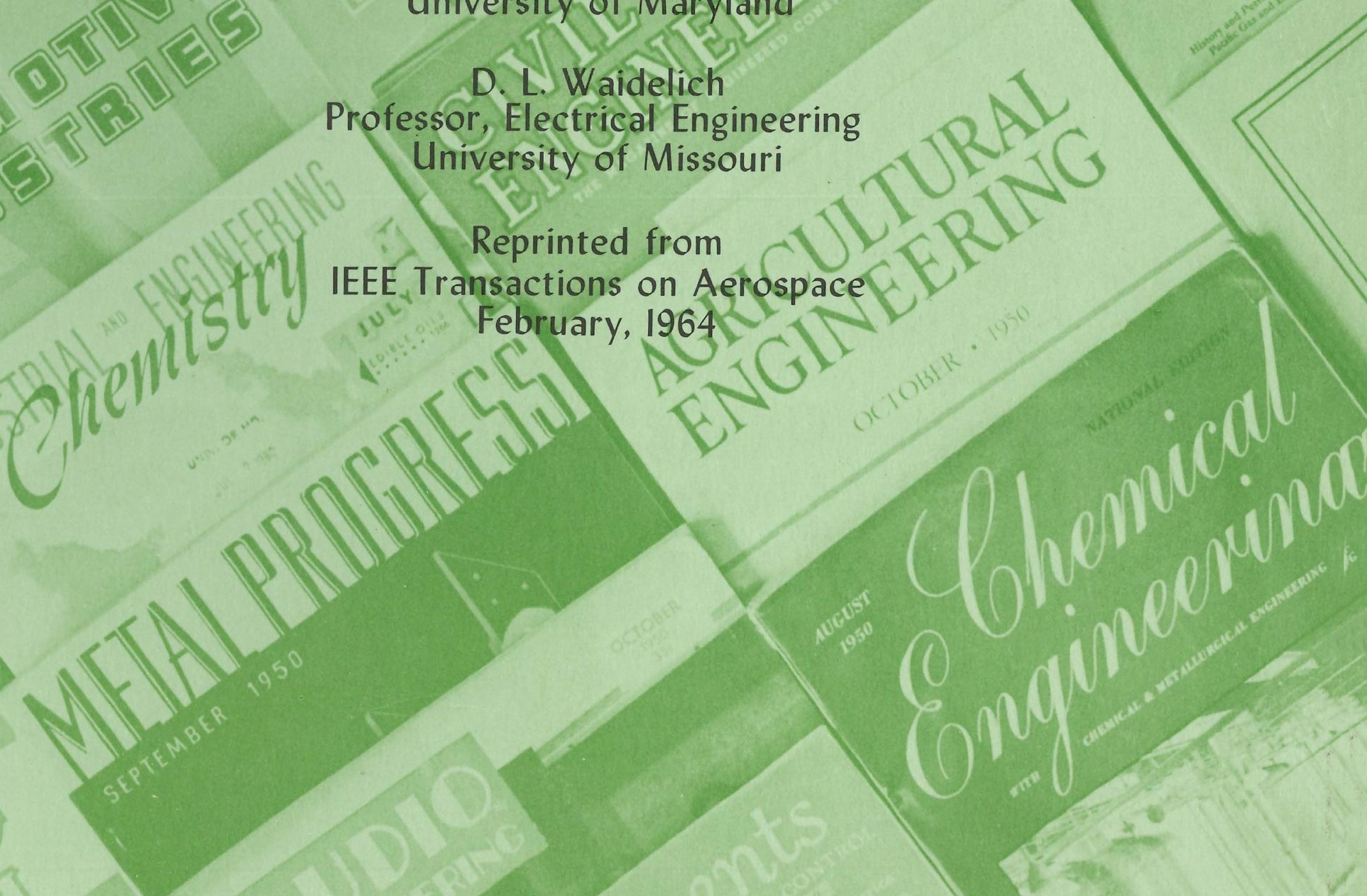




\section{COLLEGE OF ENGINEERING \\ THE ENGINEERING EXPERIMENT STATION}

The Engineering Experiment Station was organized in 1909 as a part of the College of Engineering. The staff of the Station includes all members of the Faculty of the College of Engineering, together with Research Assistants supported by the Station Funds.

The Station is primarily an engineering research institution engaged in the investigation of fundamental engineering problems of general interest, in the improvement of engineering design, and in the development of new industrial processes.

The Station desires particularly to co-operate with industries of Missouri in the solution of such problems. For this purpose, there is available not only the special equipment belonging to the Station but all of the equipment and facilities of the College of Engineering not in immediate use for class instruction.

Inquiries regarding these matters should be addressed to:

The Director

Engineering Experiment Station

University of Missouri

Columbia, Missouri

\section{THE UNIVERSITY OF MISSOURI BULLETIN}

VOL. 65, NO. 26A

ENGINEERING REPRINT SERIES

NO. 65

Published three times monthly January through May and six times monthly June through December by the University of Missouri, Office of Publications, Columbia, Missouri. Second Class postage paid at Columbia, Missouri. 


\title{
THREE AND FOUR COIL SYSTEMS FOR
}

\section{HOMOGENEOUS MAGNETIC FIELDS}

by

\author{
M. E. Pittman ${ }^{*}$ and D. L. Waidelich ${ }^{+}$
}

(Received 9/19/63)

\section{Summary:}

In the magnetic testing of satellites and spacecraft, very homogeneous fields are needed. One method of obtaining such fields is to use a number of circular coils on a common axis. The parameters of the best three-and four-coil systems were obtained by making zero as many terms as possible of the series for the field along the axis of the system. The parameters are presented in the form of tables and curves.

\section{Introduction:}

In thetesting of the magnetic properties and instruments of satellites and spacecraft, there is a need to cancel the earth's magnetic field and then produce a very homogeneous controlled magnetic field. There should be ample access to the working volume and the electrical design and construction should be as simple as possible. Since the working volume required is large, it appears as if air-core coils are the only practical solution. Most of the previous work done has been on circular coils and this will be followed here, although square coils might have some constructional advantages. The volume of homogeneity for two coils (Helmholtz pair) is so small that prohibitively large coils would be needed for the required uniformity. For four coils, a much larger volume of homogeneity may be obtained for a given size of the coils. A few special solutions have been given for the fourcoil system but no general solution over the whole range of parameters seems to have been made. It is the purpose of this paper to present such a solution and to indicate the various optimum values. The availability of a general solution will allow the design of a system when various

* Univ. of Md., College Park, Md.

+ Univ. of Mo., Columbia, Mo. factors such as the size or shape of the object being tested do not allow an optimum value to be used. In preparing for the solution of the four-coil system, it was found that the solution of the three-coil system was useful. The general solution of the three-coil system is also presented here although access to the volume of uniform field is quite limited because of the position of the center coil.

\section{Theory:}

The magnetic field of a single circular coil may be obtained by various methods such as the use of a scalar or vector magnetic potentiall,2. The magnetic field $\mathrm{H}$ along the axis of the coil is

$$
H=\sum_{n=0}^{\infty} a_{n} z^{n}
$$

where $z$ is the distance along the axis measured from the origin 0 as shown in Figure 1, $\mathrm{z}<\mathrm{b}$ and

$$
\begin{gathered}
a_{n}=\frac{N I\left(1-x^{\mid 2}\right)}{2 b^{n+1}} P_{n+1}^{\prime}(x) \\
N=\text { number of turns on the coil } \\
I=\text { current through the coil } \\
P_{n+1}^{\prime}(x)=\frac{d P_{n+1}(x)}{d x}
\end{gathered}
$$

where $P_{n}(x)$ is the $n$th order Legendre polynomial and

$$
\mathbf{x}=\cos \alpha \text {. }
$$


Two or more of the coils on a common axis may be used to produce a more homogeneous magnetic field than is possible with one coil. This is done by making as many terms zero beyond a in (1) as is possible ${ }^{34}$. The same results may be obtained by use of a potential 5,6 .

For a symmetrical four-coil system as shown in Figure 2 , the magnetic field along the axis is

$$
H=\sum_{n=0,2,4, \ldots}^{\infty} a_{n} z^{n}
$$

where

$$
a_{n}=\frac{N_{1} I_{1}\left(1-x_{1}^{2}\right)}{b_{1}^{n+1}} P_{n+1}^{\prime}\left(x_{1}\right)+\frac{N_{2} I_{2}\left(1-x_{2}^{2}\right)}{b_{2}^{n+1}} P_{n+1}^{\prime}\left(x_{2}\right)
$$

The terms for odd n's in (3) are zero because of symmetry.

\section{Three coil results:}

The three coil solution is obtained by setting $x_{1}=0$ or $a_{1}=90^{\circ}$. This has the effect of making the two inner coils of Figure 2 become the one center coil of Figure 3. With three coils it is possible to make $a_{2}$ and $a_{4}$ of (3) zero and then $a_{6}$ may be made a minimum. The solution in more detail is carried out in the appendix and the results are shown in Figures 4 and 5. Additional results are presented in Table $I$. The range of $x_{\text {f }}$ in Figures 4 and 5 is from 0.4472 to 0.7651 and the ratio of the radii $b=b_{0} / b$ ranges from infinity to zero as shown In Figure 4. This indicates that when $x_{2}$ is close to 0.4472 , the diameter of the center coil should be smaller than that of the two outer coils, while when $x_{2}$ is close to 0.7651 , the diameter of the center coil should be larger than that of the two outer coils. From Table I all three coils should have equal diameters at $x_{2}=0.6051$ while at $x_{2}=0.6547$ the three coils should lie on the surface of a sphere. The range of the ratio of ampere turns, $\mathrm{I}=\mathrm{N}_{2} \mathrm{I}_{2} / \mathrm{N}_{1} \mathrm{I}_{1}$ is infinity to zero as shown in Figure 4. Where $x_{1}=0$ the two inner coils of a four-coll system become the center coil of a three-coil system. The ampere turns on the center coil then would be $2 \mathrm{~N}_{1} \mathrm{I}_{1}$, and the actual ratio of ampere turns of an outer coil to the center coil is $\mathrm{N}_{2} \mathrm{I}_{2} / 2 \mathrm{~N}_{1} \mathrm{I}_{1}=\mathrm{I} / 2$. When $x_{2}$ is close to $2{ }^{2} 1_{0.4472}$, the ampere-turns of the center coil should be smaller than that of the outer coils, while when $x_{2}$ is close to 0.7651 , the ampere-turns of the center coil should be larger than that of the outer coils. From Table I all three coils would have equal ampere turns at $\mathrm{x}_{2}=0.6402$.

The most homogeneous field would be the one which made the remainder of the series of (3) a minimum, i.e., in

$$
H=a_{0}\left[1+\frac{a_{6}}{a_{0}} z^{6}+\frac{a_{8}}{a_{0}} z^{8}+\cdots\right]
$$

the sum of the terms in $a_{6}, a_{8}$, and so on should be a minimum. Since the term containing a 6 usually is much larger than that containing $a \&$ and any of the succeeding terms, making the a 6 term a minimum should give a close approximation to the optimum field. This may be done in a number of ways depending upon which of the parameters or combinations of the parameters are assumed to remain constant. As an example let

$$
A_{6}=b_{1}^{2} b_{2}^{4} \frac{a_{6}}{a_{0}}=\bar{b}^{6} \frac{a_{6}}{a_{0}} \text {. }
$$

In (6) if the mean radius from the center of the system $\bar{b}=\left(b_{1} b_{2}\right)^{173}$, for the three coils were constant, the a term would have its minimum at $x_{2}=0.6163$ as shown in Figure 5 and $\mathrm{Table}^{2} \mathrm{I}$. As a second example let 
$B_{6}=b_{m}^{6} \frac{a_{6}}{a_{0}}=\left\{\begin{array}{l}b_{2}^{6} \frac{a_{6}}{a_{0}}=\bar{b}^{2} A_{6} \text { when } b_{2} \geq b_{1} \\ b_{1}^{6} \frac{a_{6}}{a_{0}}=\bar{b}^{-4} A_{6} \text { when } b_{1} \geq b_{2}\end{array}\right.$

In (7) if the larger radius $b$ from the center of the system to the coils were constant, the a term would have its minimum at $x_{2}=0.6547$ as shown in Figure 5 and Table I. If the system must be 1 imited to a certain largest volume, probably the second optimum, that of $\mathrm{B}_{6}$, would be the better of the two to use. It is possible to define other optima as well but it is believed that the two mentioned above are the most useful and practical.

\section{Four coil results:}

With a four coil system such as that shown in Figure 2, it is possible to make zero $a_{2}, a_{4}$ and $a_{6}$ of (3) and to make $a_{8}$ a minimum. This solution is carried out in more detail in the appendix and the results are shown in Figures 6 and 7 and in Table II. The range of $x_{2}$ in Figures 6 and 7 is from 0.44721 to 0.87174 and the corresponding $x_{1}$ as shown in Figure 6 decreases from 0.20929 to a minimum of 0.20360 and then increases to a maximum of 0.44721 . The ratio of the radii $b=b_{2} / b_{1}$ ranges from infinity to zero as shown
in Figure 6 . Thus when $x_{\text {is }}$ is close to 0.44721 , the diameter of the two inner or No. 1 coils should be smaller than that of the two outer or No. 2 coils, while when $x_{2}$ is close to 0.87174 , the diameter of the No. 1 coils should be larger than that of the No. 2 coils. As indicated in Table II at $x_{2}=0.68519$ all four coils have the same diameter, while at $x_{2}=0.76505$ the four coils lie on the surface of a sphere and at 0.85363 both the No. 1 and No. 2 coils lie in the same plane perpendicular to the axis of the system with the No. 1 coils having the larger diameter of 3.76797 times that of the No. 2 coils. From $\mathrm{x}_{2}=0.85363$ to 0.87174 , the No. 2 coils are closer to the center of the system than the No. 1 coils. It is interesting to notice that if the No. 1 and No. 2 coils are interchanged the two end points of Table II become identical. The range of the ratio of ampere-turns, $\mathrm{I}=\mathrm{N}_{2} \mathrm{I}_{2} / \mathrm{N}_{1} \mathrm{I}_{1}$ goes from infinity to zero as shown
in Figure 6. When $x$ is close to 0.44721 the ampere-turns of the No. 1 (inner) coils would be smaller than that of the No. 2 (outer) coils while for $x_{2}$ close to 0.87174 , the ampere-turns of the No. 1 coils would be larger. All coils will have equal ampere-turns at $x_{2}=0.74207$.

The most uniform field would be the one which made the remainder of the series of (3) a minimum, i.e., in

$$
H=a_{0}\left[1+\frac{a_{8}}{a_{0}} z^{8}+\frac{a_{10}}{a_{0}} z^{10}+\cdots\right]
$$

the sum of the terms involving ${ }^{8}$, a 10 ,
etc. should be made a minimum. etc. should be made a minimum. A good that which makes the $a_{8}$ term a minimum. This may be done in a number of ways, one of which is to make the mean radius from the center of the system, $\bar{b}=\left(b_{1} b_{2}\right) 172$, constant and define

$$
A_{8}=b_{1}^{4} b_{2}^{4} \frac{a_{8}}{a_{0}}=\bar{b}^{8} \frac{a_{8}}{a_{0}} \text {. }
$$

Figure 7 shows a curve of $A_{8}$ plotted against $x_{2}$ and Table II gives some values of $\mathrm{A}_{3}$ including those at the end points. The minimum value of $A_{8}$ as given in Table II and as shown In Figure 7 is -2.21988 and occurs at $x_{2}=0.75208$ and $\mathrm{x}_{1}=0.27505$. Another way of making the $a_{8}$ term a minimum is to put

$$
B_{8}=b_{m}^{8} \frac{a_{8}}{a_{0}}=\left\{\begin{array}{l}
b_{2}^{8} \frac{a_{8}}{a_{0}} \text { when } b_{2} \geq b_{1} \\
b_{1}^{8} \frac{a_{8}}{a_{0}} \text { when } b_{1} \geq b_{2}
\end{array}\right.
$$


where $b$ is the larger radius from the center $\mathrm{m}_{\mathrm{f}}$ the system to the coils. A curve of $\mathrm{B}_{8}$ against $\mathrm{x}_{2}$ is shown in Figure 7 and some values of $\mathrm{B}_{8}$ are given in Table II. One of the values in Table II is the minimum value of $\mathrm{B}_{0}=-2.25510$ which occurs at $x_{2}=0.76505$ and $x_{1}=0.28523$. If more than one term is considered in the series of (8), the miniinum depends upon the magnitude of $\mathrm{z}$. - For example if the $a_{8}$ and $a_{1}$ terms are considered in (8) they may be written as

$$
\begin{aligned}
\left(\bar{b}^{8} \frac{a_{8}}{a_{0}}\right)\left(\frac{z}{\bar{b}}\right)^{8}+\left(\bar{b}^{10} \frac{a_{10}}{a_{0}}\right)\left(\frac{z}{\bar{b}}\right)^{10} & =A_{8}\left(\frac{z}{\bar{b}}\right)^{8}+A_{10}\left(\frac{z}{\bar{b}}\right)^{10} \\
& =C\left(\frac{z}{\bar{b}}\right)^{8}
\end{aligned}
$$

where

$$
\begin{aligned}
& A_{10}=\bar{b}^{10} \frac{a_{10}}{a_{0}}=b_{1}^{5} b_{2}^{5} \frac{a_{10}}{a_{0}} \\
& C=A_{8}+A_{10}\left(\frac{z}{\bar{b}}\right)^{2} .
\end{aligned}
$$

The minimum value of $\mathrm{C}$ is the same as the minimum value of $A_{8}$ when $z=0$ but when $\mathrm{z} / \overline{\mathrm{b}}=0.2167$, the minimum value of $\mathrm{C}$ occurs at $x_{2}=0.74842$ and $x_{1}=0.27235$ as given in Table II.

There are several other well known four coil solutions which do not have as great a uniformity as the solutions given in Figures 6 and 7 and in Table II because only two coefficients of (3) namely, $\mathrm{a}_{2}$ and $a_{4}, 6$ are made zero, $A s$ an example Neumann 6 and Fanselau4, 8 , put $x_{1}$ and $x_{2}$ at the roots of $\mathrm{P}_{5}^{\prime}(\mathrm{x})=0$ to make $\mathrm{a}_{\text {zerd, }}$, then chose the ampere-turns of both No. 1 and No. 2 coils equal and found $b$ by putting $a_{2}=0$. Further details are given in Table III. Fanselaulo in another solution made $a_{4}$ zero by using the roots of $\mathrm{P}_{5}^{\prime}(\mathrm{x})=0.4$ Both coils on one side of the system were put in the same plane perpendicular to the axis of the system and $a_{2}$ was made zero by choosing $I=28.2897$. The ratio of the diameter of the smaller coil to that of the larger coil was 0.250495 and $b=0.372830$. Fanselau also indicated that a similar solution could be made where both sets of coils would have the same radius. Several additional four coil solutions with both $\mathrm{a}_{2}$ an $_{11} \mathrm{a}_{4}$ zero are given by McKeehan. Scott
used four coils with the inner pair having a smaller diameter than the outer pair. His solution had both $a_{2}$ and $a_{45}$ zero. Franzen 12 used Garrett' $\xi$ theory 5 to develop a theory of finite coil crosssection for a four coil system.

In Table III is presented the specifications of several coil systems along with an indication of how large a sphere about the center of the system will have a given homogeneity. Several three-and four-coil systems are given along with the two coil system of Helmholtz and the presently known six- and eight-coil systems. These are compared on a basis of an inhomogeneity of $10^{-5}$ and as an example choose the minimum $A_{8}$ solution for the four-coil system. Then

$$
\left|A_{8}\left(\frac{z}{\bar{b}}\right)^{8}\right|=10^{-5}
$$

and

$$
\left(\frac{z}{\bar{b}}\right)=0.21677 \text { or } 21.677 \%
$$

This means that if $\overline{\mathrm{b}}=10$ feet and considering only the $A_{8}$ term, the inhomogeneity of the magnetic field inside a sphere of 2.1677 feet radius would be less than or equal to $10^{-5}$ or $0.001 \%$ If $\mathrm{B}_{8}$ were used

$$
\left|B_{8}\left(\frac{z}{b_{m}}\right)^{8}\right|=10^{-5}
$$

and 


$$
\left(\frac{z}{b_{m}}\right)=0.20944 \text { or } 20.944 \% \text {. }
$$

The ampere-turns in the middle coil of the three coil system should be $2 \mathrm{~N}_{1} \mathrm{I}_{1}$. For the six-coil systems, the $x^{\prime} s$ for the Neumann-Fanselau and the Williams-Cain solutions are the roots of $P_{7}^{\prime}(x)=0$. Similarly for the eight-coil systems, the $x$ 's for the Neumann-McKeehan and the Williams-Cain solutions are the roots of $\mathrm{P}^{\prime}(\mathrm{x})=0$; Similar solutions using the roots of $\mathrm{P}^{i}(\mathrm{x})=0$ where $\mathrm{n}$ is even could be made for systems containing ten, twelve or higher ( $n$ ) number of coils9. In fact Garrett 5 mentions the fact that the solution for a sixteen-coil system could be made readily. The Williams-Cain solution always gives the optimum solution for minimum $\mathrm{B}_{2 \mathrm{n}}$.

\section{Conclusions:}

Complete solutions along with tables and curves that should be useful in design work have been presented for the three and four circular-coil systems with zero crosssectional area of the coils. Comparisons of these results have been made with the two-coil (Helmholtz) and the known six and eight coil systems. At the present time there is needed:

1. A complete study of the six-coil problem over the ranges of all of the parame ters.

2. An investigation of the square or rectangular coil systems.

3. An analysis of the effect of finite cross-sectional area of the coils.

\section{References}

1. Smythe, W. R., "Static and Dynamic Electricity" Second Edition, pages 270 to 275, McGraw-Hill Book Co., New York, N. Y. 1950 .

2. Booker, H. G., "An Approach to Electrical Science", McGraw-Hill Book Co., New York, N. Y., 1959, pages 449 to 472.
3. Barker, J. R., "New Coil Systems for the Production of Uniform Magnetic Fields", Journal of Scientific Instruments, volume 26 , pages 273 to 275 , August 1949.

4. Sauter, A. and F., "Die Erzeugung von möglichst homogenen Magnetfelden durch Stromsysteme", Zeitschrift furr Physik, volume 122, pages 120 to $136,1944$.

5. Garrett, M. W., "Axially Symmetric Systems for Generating and Measuring Magnetic Fields, Part I", Journal of Applied Physics, volume 22, pages 1091 to 1107, September 1951.

6. McKeehan, L. W., "Combinations of Circular Currents for Producing Uniform Magnetic Fields", Review of Scientific Instruments, volume 7 , pages 150 to 153, March 1936.

7. Braunbek, W., "Die Erzeugung weitgehend homogener Magnetfelder durch Kreisstrome", Zeitschrift fur Physik, volume 88, pages 399 to 402, 1934.

8. Fanselau, G., "Die Erzeugung weitgehend homogener Magnetfelder durch Kreisströme", Zeitschrift fur Physik, volume 54, pages 260 to $269,1929$.

9. Williams, V. L., and Cain, J. C., "Homogeneous Magnetic Fields Produced by Circular Current Loops", unpublished memorandum, Goddard Space Flight Center, Greenbe1t, Maryland.

10. Fanselau, G., "Über die Homogenitut des Magnetfeldes bei symmetrischer Spulenanordnung" Zeitschrift fur Geophysik, volume 9, pages 236 to 237 , 1933.

11. Scott, G. G., "Compensation of the Earth 's Magnetic Field", Review of Scientific Instruments, volume 28 , pages 270 to $273,1957$.

12. Franzen, W., "Generation of Uniform Magnetic Fields by Means of Air-Core Coils", Review of Scientific Instruments, volume 33, pages 933 to 938, September 1962 . 
APPENDIX

Solution of the coil systems

\section{Three coil system}

Put $x_{1}=0$ in (4) and let $b=b_{2} / b_{1}$ and $I=N_{2} I_{2} / N_{1} I_{1}$. Then for $n=2$ and $n=4$ in $(4)$ :

$$
\begin{aligned}
& \left(-\frac{3}{2}\right) b^{3}+I\left(1-x_{2}{ }^{2}\right) P_{3}^{\prime}\left(x_{2}\right)=0 \\
& \left(\frac{15}{8}\right) b^{5}+I\left(1-x_{2}{ }^{2}\right) P_{3}^{\prime}\left(x_{2}\right)=0
\end{aligned}
$$

where

$$
P_{3}^{\prime}\left(x_{2}\right)=\left(\frac{3}{2}\right)\left(5 x_{2}^{2}-1\right)
$$

and

$$
P_{5}^{\prime}\left(x_{2}\right)=\left(\frac{15}{8}\right)\left(21 x_{2}^{4}-14 x_{2}^{2}+1\right)
$$

From $(A-1)$ and $(A-2)$ :

$$
\frac{I\left(1-x_{2}^{2}\right)}{b^{3}}=\frac{\left(+\frac{3}{2}\right)}{P_{3}^{\top}\left(x_{2}\right)}=\frac{\left(-\frac{15}{8}\right) b^{2}}{P_{5}^{\prime}\left(x_{2}\right)}
$$

From $(A-3)$

$$
\begin{aligned}
b^{2} & =\frac{1-14 x_{2}{ }^{2}+21 x_{2}^{4}}{1-5 x_{2}^{2}} \\
I & =\frac{b^{3}}{\left(1-x_{2}{ }^{2}\right)\left(5 x_{2}{ }^{2}-1\right)}
\end{aligned}
$$

In $(A-4) b^{2}$ must be positive so the only possible solutions must have $0.0 \leq x_{2} \leq 0.2852$ or $0.4472 \leq x_{2} \leq 0.7651$ where 0.4472 is the root of $P_{3}^{\prime}\left(x_{2}\right)=0$ and 0.2852 and 0.7651 are the roots of $P_{5}^{\prime}\left(x_{2}\right)=0$. The range of values of $x_{2}$ from 0.4472 to 0.7651 produces positive values of I while the range from 0.0 to 0.2852 produces negative values of $I$. A negative value of $I$ means that the currentdirection in the center coil is reversed from those in the two outer coils.

For the $a_{6}$ term of $(3)$ let

$$
A_{6}=b_{1}{ }^{2} b_{2}{ }^{4} \frac{a_{6}}{a_{0}}=b^{4} b_{1}{ }^{6} \frac{{ }^{16}}{a_{0}}
$$

where $a_{6}$ and $a_{0}$ are given by (2). Then by the use of (4), (A-4) and $(A-5)$

$$
A_{6}=-\frac{7}{16}\left(\frac{15 x_{2}^{6}-9 x_{2}^{4}+5 x_{2}^{2}+5}{x_{2}^{2}+1}\right)
$$

The value of $x_{2}$ at which $(A-7)$ has its minimum value is 0.6163 . This value of $x_{2}$ is in the range for which $I$ is positive. Hence nr the threecil solution at least, making all currents flow in the same direction will produce a more homogeneous field. Another minimum value may be obtained by defining

$$
B_{6}=\left\{\begin{array}{l}
b_{2}^{6} \frac{a_{6}}{a_{0}}=\bar{b}^{2} A_{6} \text { for } 0.4475 \leq x_{2} \leq 0.6547 \\
b_{1}^{6} \frac{a_{6}}{a_{0}}=\frac{A_{6}}{\bar{b}} \text { for } 0.6547 \leq x_{2} \leq 0.7651
\end{array}\right.
$$

where $\bar{b}=1.0$ at $x_{2}=0.6547$. Then the minimum value of $B_{6}$ occurs at $x_{2}=0.6547$

2. Four coil system

For $n=2,4,6$ from (4) and putting $b=b_{2} / b_{1}$ and $I=N_{2} I_{2} / N_{1} I_{1}$ :

$$
b^{3}\left(1-x_{1}^{2}\right) P_{3}^{\prime}\left(x_{1}\right)+I\left(1-x_{2}^{2}\right) P_{3}^{\prime}\left(x_{2}\right)=0
$$$$
b^{5}\left(1-x_{1}^{2}\right) P_{5}^{\prime}\left(x_{1}\right)+I\left(1-x_{2}^{2}\right) P_{3}^{\prime}\left(x_{2}\right)=0
$$

$$
b^{\prime}\left(1-x_{1}^{2}\right) P_{7}^{\prime}\left(x_{1}\right)+I\left(1-x_{2}^{2}\right) P_{7}^{\prime}\left(x_{2}\right)=0
$$

where

$$
P_{i}^{\prime}\left(x_{1}\right)=\frac{7}{16}\left(429 x_{1}^{6}-495 x_{1}^{4}+135 x_{1}^{2}-5\right)
$$

and $P_{3}^{\prime}$ and $P_{5}^{\prime}$ are given under $(A-2)$. From $(A-9),(A-10)$ and $(A-11)$

$$
\frac{I\left(1-x_{2}^{2}\right)}{b^{3}\left(1-x_{1}{ }^{2}\right)}=-\frac{P_{3}^{\prime}\left(x_{1}\right)}{P_{3}^{\prime}\left(x_{2}\right)}=-\frac{b^{2} P_{5}^{\prime}\left(x_{1}\right)}{P_{3}^{\prime}\left(x_{2}\right)}=-\frac{b^{4} P_{7}^{\prime}\left(x_{1}\right)}{P_{7}^{\prime}\left(x_{2}\right)}
$$

From $(A-12)$ :

$$
b^{2}=\frac{P_{3}^{\prime}\left(x_{1}\right) P_{5}^{\prime}\left(x_{2}\right)}{P_{3}^{\prime}\left(x_{2}\right) P_{5}^{\prime}\left(x_{1}\right)}=\frac{P_{5}^{\prime}\left(x_{1}\right) P_{7}^{\prime}\left(x_{2}\right)}{P_{5}^{\prime}\left(x_{2}\right) P_{7}^{\prime}\left(x_{1}\right)}
$$

From $(A-13)$ :

$$
\frac{P_{3}^{\prime}\left(x_{1}\right) P_{7}^{\prime}\left(x_{1}\right)}{\left[P_{5}^{\prime}\left(x_{1}\right)\right]^{2}}=\frac{P_{3}^{\prime}\left(x_{2}\right) P_{7}^{\prime}\left(x_{2}\right)}{\left[P_{5}^{\prime}\left(x_{2}\right)\right]^{2}}=f\left(x_{2}\right)
$$

or

$$
P_{3}^{\prime}\left(x_{1}\right) P_{7}^{\prime}\left(x_{1}\right)-f\left(x_{2}\right)\left[P_{3}^{\prime}\left(x_{1}\right)\right]^{2}=0
$$

For a given $x_{2},(A-15)$ was solved for $x_{1}$ and the ratio of the radii b was obtained from (A-13). The ampere-turn ratio I may be obtained by the use of $(A-12)$ :

$$
I=-\frac{b^{3}\left(1-x_{1}^{2}\right) P_{3}^{\prime}\left(x_{1}\right)}{\left(1-x_{2}^{2}\right) P_{3}^{\prime}\left(x_{2}\right)}
$$


The use of a computer allowed numerous solutions to be obtained over the range for $x_{2}$ from 0.4472 which is a root of $P_{3}^{\prime}(x)=0$ to 0.8717 which is a root of $P_{i^{\prime}}^{\prime}(x)=0$. The corresponding $r$ ange for $x_{1}$ is from 0.2036 is a root of $P_{7}(x)=0$. The corresponding $r$ ange for $x_{1}$ is from 0.4472 . For these values $I$ is positive. I may be negative when both $x_{1}$ and $x_{2}$ lie in the range between 0.4472 and 0.5917 where 0.5917 is a root of $P_{7}^{\prime}(x)=0$. The values for I negative were not calculated be cause the more useful values were in the range where $I$ is positive.

For the $a_{8}$ term of (3) let

$$
A_{B}=b_{1}^{4} b_{2}^{4} \frac{a_{B}}{a_{0}}
$$

where $a_{8}$ and $a_{0}$ are given by (2). Then by the use of $(4),(A-13)$ and $(A-16)$

$A_{8}=\frac{P_{3}^{\prime}\left(x_{1}\right) P_{5}^{\prime}\left(x_{2}\right) P_{7}^{\prime}\left(x_{2}\right) P_{9}^{\prime}\left(x_{1}\right)-P_{3}^{\prime}\left(x_{2}\right) P_{5}^{\prime}\left(x_{1}\right) P_{7}^{\prime}\left(x_{1}\right) P_{9}^{\prime}\left(x_{2}\right)}{P_{3}^{\prime}\left(x_{2}\right) P_{5}^{\prime}\left(x_{2}\right) P_{7}^{\prime}\left(x_{1}\right)-P_{3}^{\prime}\left(x_{1}\right) P_{5}^{\prime}\left(x_{1}\right) P_{7}^{\prime}\left(x_{2}\right)}$

where

$$
P_{g}^{\prime}(x)=\frac{45}{128}\left(2431 x^{8}-4004 x^{6}+2002 x^{4}-308 x^{2}+7\right)
$$

The minimum value of $\left|A_{8}\right|$ is 2.21989 and occurs at $x_{1}=0.27505$ and $x_{2}=0.75209$. If the sum of both the $a_{8}$ and $a_{10}$ terms is minimized the minimum occurs at $x_{1}=0.27235$ and $x_{2}=0.74841$. Again another minimum may be defined by taking

$$
B_{8}=\left\{\begin{array}{l}
b_{2}^{8} \frac{a_{8}}{a_{0}}=\bar{b}^{4} A_{8} \text { when } x_{2} \leq 0.76505 \\
b_{1}^{8} \frac{a_{8}}{a_{0}}=\frac{A_{8}}{\bar{b}^{4}} \text { when } x_{2} \geq 0.76505
\end{array}\right.
$$

The minimum value of $B_{8}$ occurs at $x_{1}=0.28523$ and $x_{2}=0.76505$. The next term in the series has

$$
A_{10}=b_{1}^{3} b_{2}^{3} \frac{a_{10}}{a_{0}}
$$

where $a_{10}$ and $a_{0}$ are given by (2).

If solutions of greater accuracy are needed than those available in the curves and tables here presented, they may be obtained by numerical solution of the equations given in the appendix using the present solutions as a starting point.

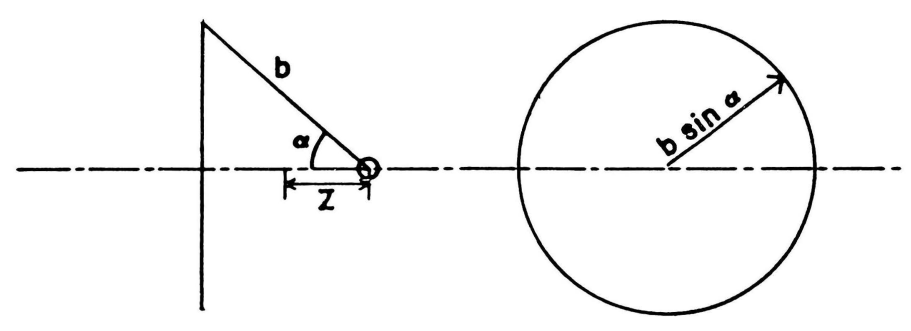

Figure 1 - The single circular coil

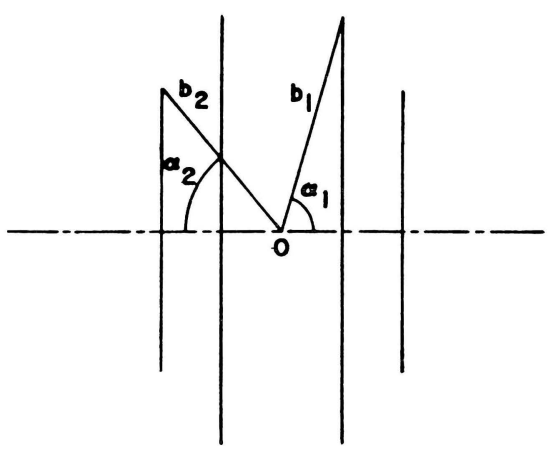

Figure 2 - The four-coil system

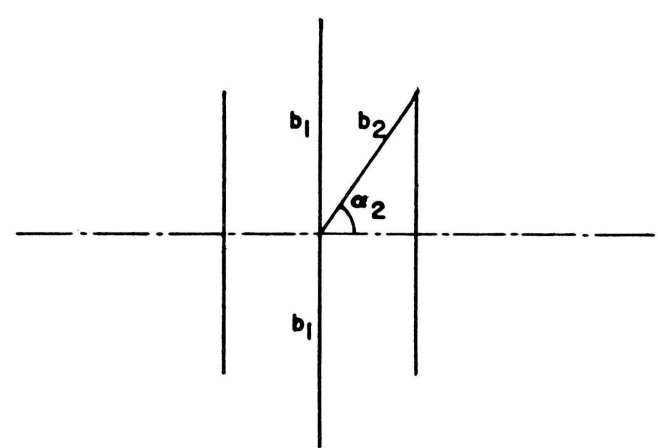

Figure 3 - The three-coil system 


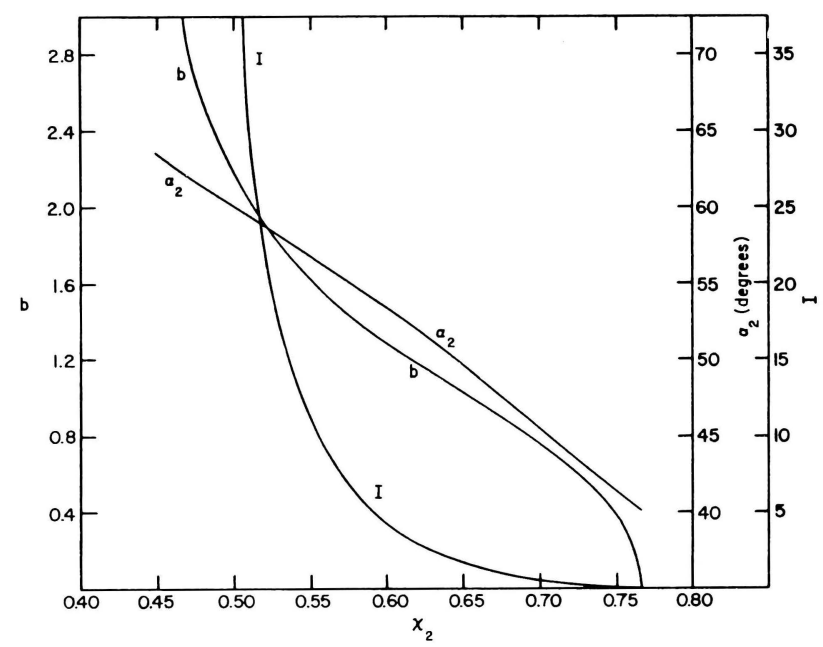

Figure 4 - Calculated values of $d_{2}$, I and $b$ for the three-coil system

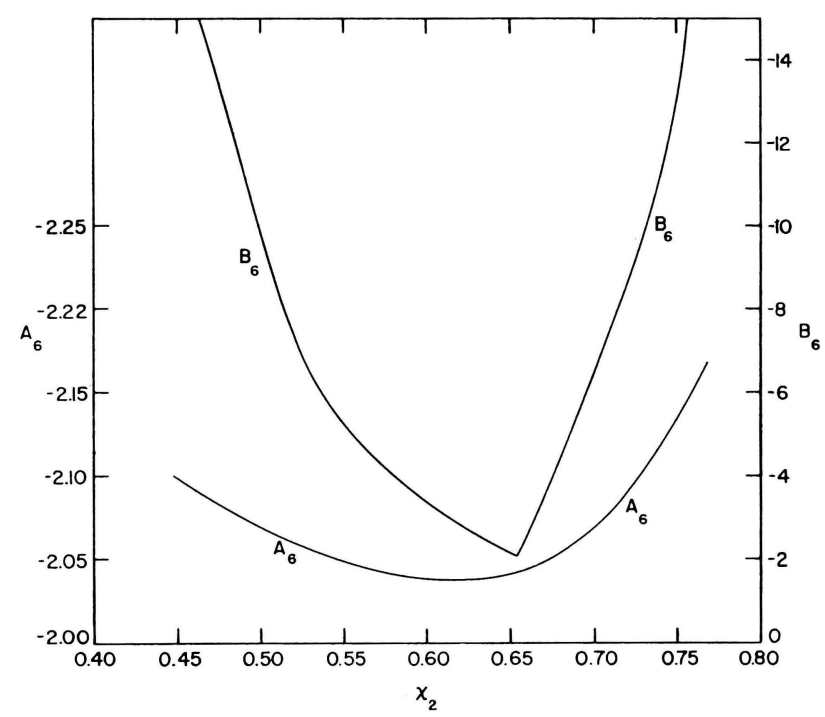

Figure 5 - Calculated values of $A_{6}$ and $B_{6}$ for the three-coil system

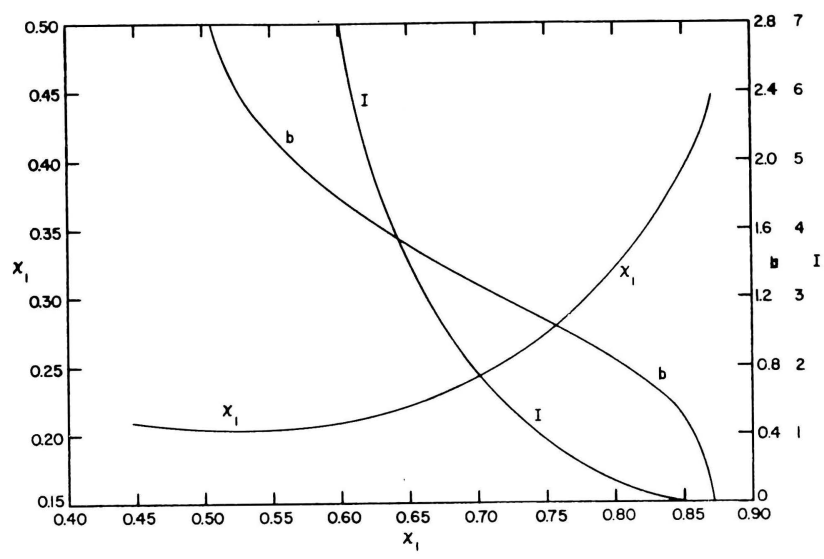

Figure 6 - Calculated values of $\mathrm{x}$, I and $\mathrm{b}$ for the four-coil system

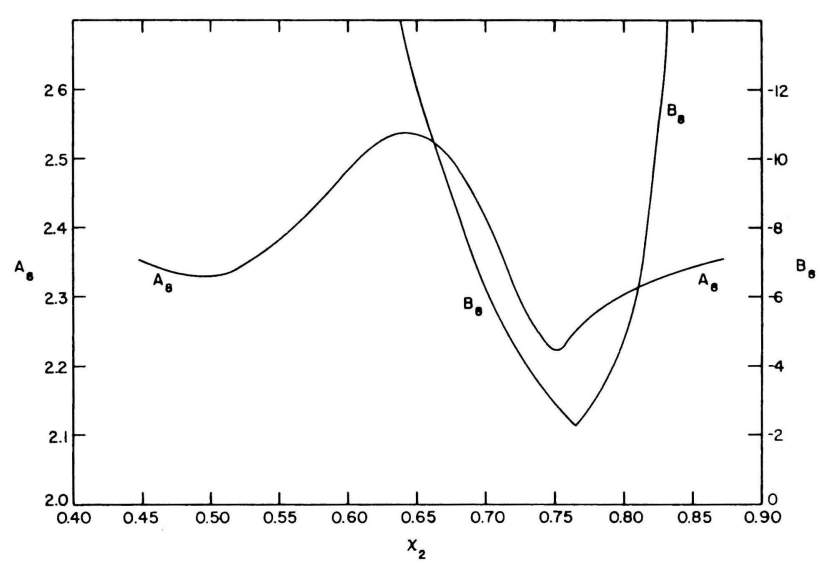

Figure 7 - Calculated values of $A_{8}$ and $B_{8}$ for the four-coil system 
Table I

Particular Three-Coil Systems

\begin{tabular}{|c|c|c|c|c|c|c|}
\hline$x_{2}$ & $a_{2}$ (degrees) & b & $\mathbf{I}$ & $A_{6}$ & $B_{6}$ & Remarks \\
\hline 0.4472 & $63.42^{\circ}$ & $\infty$ & $\infty$ & -2.100 & $-\infty$ & End point \\
\hline 0.6051 & $52.76^{\circ}$ & 1.256 & 3.763 & -2.0369 & -3.214 & $\begin{array}{l}\text { Coils of equal diameter } \\
\text { Barker's solution }\end{array}$ \\
\hline 0.6163 & $51.96^{\circ}$ & 1.197 & 3.076 & -2.0364 & -2.925 & Minimum $\left|A_{6}\right|$ \\
\hline 0.6402 & $50.19^{\circ}$ & 1.074 & 2.000 & -2.0388 & -2.351 & Coils of equal ampere-turns \\
\hline 0.6547 & $49.10^{\circ}$ & 1.000 & 1.531 & -2.043 & -2.043 & $\begin{array}{l}\text { Minimum }\left|\mathrm{B}_{6}\right| \text { Maxwell's } \\
\text { solution } 6 \text { Coils on surface } \\
\text { of sphere }\end{array}$ \\
\hline 0.7651 & $40.08^{\circ}$ & 0.000 & 0.000 & -2.167 & $-\infty$ & End point \\
\hline
\end{tabular}

Table II

Particular Four-Coil Systems

\begin{tabular}{|c|c|c|c|c|c|c|}
\hline$x_{1}$ & $\mathbf{x}_{2}$ & b & I & $\mathbf{A}_{8}$ & $\mathbf{B}_{\mathbf{8}}$ & Remarks \\
\hline 0.20929 & 0.44721 & $\infty$ & $\infty$ & -2.35384 & $-\infty$ & End point \\
\hline 0.20360 & 0.51961 & 2.49155 & 46.00025 & -2.34170 & $-90: 24299$ & Minimum $\mathbf{x}_{1}$ \\
\hline 0.23629 & 0.68519 & 1.33407 & 2.26058 & -2.47133 & -7.82798 & $\begin{array}{l}\text { All coils have equal diameters } \\
\text { Barker's solution }{ }^{3}\end{array}$ \\
\hline 0.26786 & 0.74207 & 1.09795 & 1.000 & -2.23448 & -3.24721 & $\begin{array}{l}\text { All coils have equal ampere-turns } \\
\text { Braunbek's solution } 6,7\end{array}$ \\
\hline 0.27235 & 0.74842 & 1.07127 & 0.90406 & -2.22196 & -2.92648 & Optimum using both $A_{8}$ and $A_{10}$ terms \\
\hline 0.27505 & 0.75208 & 1.05576 & 0.85165 & -2.21988 & -2.75803 & Optimum using $A_{8}$ only \\
\hline 0.28523 & 0.76505 & 1.000 & 0.68211 & -2.25510 & -2.25510 & $\begin{array}{l}\text { All coils on surface of a sphere } \\
\text { Optimum using } \mathrm{B}_{8} \text {. McKeehan's } \\
\text { solution5.6 }\end{array}$ \\
\hline 0.39864 & 0.85363 & 0.46699 & 0.024569 & -2.34225 & -49.24825 & $\begin{array}{l}\text { Both No. } 1 \text { and No. } 2 \text { coils lie in the } \\
\text { same plane perpendicular to the axis } \\
\text { of the system }\end{array}$ \\
\hline 0.44721 & 0.87174 & 0.000 & 0.000 & -2.35384 & $-\infty$ & End point \\
\hline
\end{tabular}


Table 3

Specifications of Various Coil Systems.

\begin{tabular}{|c|c|c|c|c|c|c|}
\hline \multicolumn{2}{|l|}{ Source } & $\begin{array}{c}\text { Ampere } \\
\text { (Reference 6) }\end{array}$ & $\begin{array}{c}\text { Helmholtz } \\
\text { (Reference 6) }\end{array}$ & $\begin{array}{c}\text { Barker } \\
\text { (Reference 3) }\end{array}$ & $\begin{array}{c}\text { Maxwell } \\
\text { (Reference 6) }\end{array}$ & Minimum $A_{6}$ \\
\hline \multicolumn{2}{|l|}{ Number of Coils } & 1 & 2 & 3 & 3 & 3 \\
\hline \multicolumn{2}{|l|}{ Assumptions } & None & None & Equal diameter coils & Coils on surface of sphere & None \\
\hline \multicolumn{2}{|c|}{ The a's that are zero } & None & $a_{2}$ & $a_{2}, a_{4}$ & $a_{2}, a_{4}$ & $a_{2}, a_{4}$ \\
\hline \multicolumn{2}{|c|}{ Coefficient of next term, $A_{n}$} & -1.5 & -1.8 & -2.03689 & -2.0428571 & -2.036420 \\
\hline \multicolumn{2}{|l|}{$\mathrm{x}_{2}$} & - & - & 0.605108 & 0.6546537 & 0.61627 \\
\hline \multicolumn{2}{|l|}{$b$} & - & - & 1.25606 & 1.00 & 1.19697 \\
\hline \multicolumn{2}{|l|}{1} & - & - & 3.76323 & 1.53125 & 3.075846 \\
\hline \multirow{2}{*}{$\begin{array}{l}\text { For an } \\
\text { inhomogeneity } \\
\text { of } 10^{-5} \text { (percent) }\end{array}$} & $2 / \bar{b}$ & 0.26 & 4.86 & 13.0368 & 13.031 & 13.0373 \\
\hline & $z / b_{m}$ & 0.26 & 4.86 & 12.083 & 13.031 & 12.279 \\
\hline
\end{tabular}

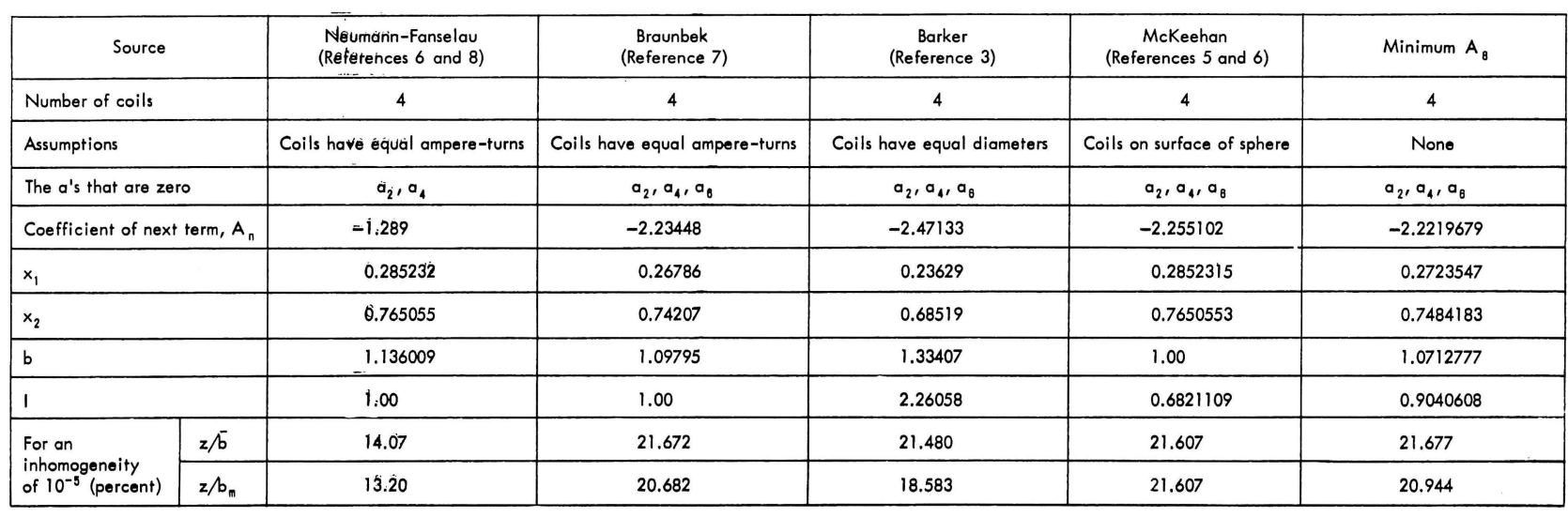

\begin{tabular}{|c|c|c|c|c|c|c|}
\hline \multicolumn{2}{|l|}{ Source } & $\begin{array}{l}\text { Neumann-Fanselau } \\
\text { (References } 6 \text { and } 8 \text { ) }\end{array}$ & $\begin{array}{l}\text { Brounbek-McKeohan } \\
\text { (Reforences } 6 \text { and } 7 \text { ) }\end{array}$ & $\begin{array}{l}\text { Williams-Cain } \\
\text { (Reforence 9) }\end{array}$ & $\begin{array}{c}\text { Noumann-MeKoehan } \\
\text { (Reforence 6) }\end{array}$ & $\begin{array}{l}\text { Williams-Cain } \\
\text { (Roforence 9) }\end{array}$ \\
\hline \multicolumn{2}{|l|}{ Number of coils } & $\theta$ & 6 & 6 & 8 & 8 \\
\hline \multicolumn{2}{|l|}{ Assumptions } & Colls have equal ampere-turns & Colls have equal ampere-turns & Colls lie on surface of sphere & $\begin{array}{l}\text { Coils have equal } \\
\text { ampere-turns }\end{array}$ & Coils lie on surface of sphere \\
\hline \multicolumn{2}{|c|}{ The a's that are zero } & $a_{2}, a_{4}, a_{0}$ & $a_{2}$ to $a_{10}$ & $a_{2}$ to $a_{10}$ & $a_{2}$ to $a_{\theta}$ & $a_{2}$ to $a_{14}$ \\
\hline \multicolumn{2}{|l|}{$x_{1}$} & 0.20929922 & 0.190655 & 0.20929922 & 0.1652754 & 0.1652754 \\
\hline \multicolumn{2}{|l|}{$x_{2}$} & 0.59170018 & 0.550274 & 0.59170018 & 0.4779250 & 0.4779250 \\
\hline \multicolumn{2}{|l|}{$x_{3}$} & 0.87174003 & 0.843307 & 0.87174003 & 0.7387739 & 0.7387739 \\
\hline \multicolumn{2}{|l|}{$x_{4}$} & - & - & - & 0.9195342 & 0.9195342 \\
\hline \multicolumn{2}{|l|}{$b_{2} / b_{1}$} & 1.071723 & 1.046147 & 1.00 & 1.0222398 & 1.00 \\
\hline \multicolumn{2}{|l|}{$b_{3} / b_{1}$} & 1.242359 & 1.157907 & 1.00 & 1.1827288 & 1.00 \\
\hline \multicolumn{2}{|l|}{$b_{4} / b_{1}$} & - & - & - & 1.2382935 & 1.00 \\
\hline \multicolumn{2}{|l|}{$\mathrm{N}_{2} \mathrm{I}_{2} / \mathrm{N}_{1} \mathrm{I}_{1}$} & 1.00 & 1.00 & 0.8270469 & 1.00 & 0.891626 \\
\hline \multicolumn{2}{|l|}{$N_{3} I_{3} / N_{1} I_{1}$} & 1.00 & 1.00 & 0.5108492 & 1.00 & 0.686604 \\
\hline \multicolumn{2}{|l|}{$\mathrm{N}_{4} I_{4} / \mathrm{N}_{1} \mathrm{I}_{1}$} & - & - & - & 1.00 & 0.406992 \\
\hline $\begin{array}{l}\text { For an } \\
\text { inhomogeneity } \\
\text { of } 10^{-8} \text { (percent) }\end{array}$ & $z / b_{m}$ & 31 & 34 & 36 & 16 & 47 \\
\hline
\end{tabular}






\section{PUBLICATIONS OF THE ENGINEERING REPRINT SERIES}

Copies of publications may be secured from the Director of the Engineering Experiment Station, University of Missouri. Single copies may be obtained free unless otherwise indicated until the supply is exhausted. Requests for additional copies will be considered upon further inquiry.

\section{Reprint No.}

53. Thermodynamic Properties of n-Propyl Alconol by J. L. Cosner, Graduate Student, Department of Chemical Engineering, University of Missouri, J. E. Gagliardo, Student Assistant in Chemical Engineering, University of Missouri and T. S. Storvick, P. E., Assistant Professor of Chemical Engineering, University of Missouri, Reprinted from Journal of Chemical \& Engineering Data, Vol. 6, No. 3 July, 1961.

54. An Evaluation of the Overhead Projector in Teaching Kinematics by Richard P. Covert, Associate Professor of Industrial Engineering, Reprinted from The Journal of Engineering Education, Vol. 51, No. 10, June 1961.

55. Transfer of Load Between Precast Bridge Slabs by Adrian Pauw, P.E. and John E. Breen, Assistant Professor, Department of Civil Engineering, University of Missouri, Reprinted from Bulletin 279 (1961) Highway Research Board, Washington, D.C.

56. The Present Status of Structural Lightweight Concrete in the U.S.A. by Adrian Pauw, P.E., Professor of Civil Engineering, University of Missouri. Reprinted from "De Ingenieur," Vol. 73, No. 34, Aug. 25, 1961, The Netherlands.

57. Field Testing of Two Prestressed Concrete Girders by Adrian Pauw, Professor of Civil Engineering, University of Missouri, and John E. Breen, Instructor in Civil Engineering, University of Missouri. Reprinted from Highway Research Board Bulletin 307, National Academy of Sciences--National Research Council Publication 937, pages 42-63, 1961.

58. Controlled-Deflection Design Method for Reinforced Concrete Beams and Slabs by Adrian Pauw, Professor of Civil Engineering, University of Missouri. Reprinted from Journal of The American Concrete Institute, Vol. 59, No. 5, May 1962.

59. The Impedance of a Coil Placed on a Conducting Plane by T. J. Russell, The Bendix Corporation, Kansas City, Missouri, V. E. Schuster, Motorola, Inc., Phoenix, Arizona and D. L. Waidelich, Professor of Electrical Engineering, University of Missouri. Reprinted from AIEE Winter General Meeting, New York, N. Y., January 28 - February 2, 1962.

60. Discussion of an Article by G. S. Ramaswamy and M. Ramaiah: Characteristic Equation of Cylindrical Shells--A Simplified Method of Solution by Adrian Pauw, Professor of Civil Engineering, University of Missouri, and W. M. Sangster, Professor of Civil Engineering, University of Missouri. Reprinted from Journal of The American Concrete Institute Concrete Briefs, pages 1505-1509, October 1962.

61. Dissolution Rates of Uranium Dioxide Sintered Pellets in Nitric Acid Systems by R. F. Taylor, Chemical Engineering Division, AERE, Harwell, England, E. W. Sharratt, Chemical Engineering Division, AERE, Harwell, England, L. E. M. de Chazal, Associate Professor Chemical Engineering and D. H. Logsdail, Chemical Engineering Division, AERE, Harwell, England. Reprinted from Journal of Applied Chemistry, Published by the Society of Chemical Industry, Volume 13, No. 1, January 1963, Pages 32-40.

62. Circuit Waveforms for Periodic Waves by D. L. Waidelich, Professor, Electrical Engineering, University of Missouri. Reprinted from Communication and Electronics, March $1 y 63$.

63. Transmission Losses and Economy Loading by the Use of Admittance Constants by J. R. Tudor, Associate Professor, Electrical Engineering, University of Missouri and W. A. Lewis, Research Professor, Electrical Engineering, Illinois Institute of Technology, Chicago, Illinois. Reprinted from Power Apparatus and Systems, IEEE, October, 1963.

64. Applicability of Thermoacoustic Phenomena to MHD Conversion Systems by R. L. Carter, Professor, Electrical Engineering, University of Missouri, K. T. Feldman, Jr., NDEA Fellow, Mechanical Engineering, University of Missouri, and C. N. McKinnon, Jr., Instructor, Mechanical Engineering, University of Missouri. Reprinted from Fifth Symposium on the Engineering Aspects of Magnetohydrodynamics MIT, April 1 \& 2, 1964.

65. Three and Four Coil Systems for Homogeneous Magnetic Fields by M. E. Pittman, Research Assistant, Physics Department, University of Maryland, D. L. Waidelich, Professor, Electrical Engineering, University of Missouri. Reprinted from IEEE Transactions on Aerospace, February, 1964. 


\section{The University of Missouri SCHOOLS AND COLLEGES}

For the Divisions at Columbia:

COllege of Agriculture

SCHOOL OF FORESTRY

SCHOOL OF HOME ECONOMICS

COllege of ARTS AND SCIENCE

SCHOOL OF SOCIAL WORK

School of Business and Public Administration

College of Education

COlLEGE OF ENGINEERING

ENGINEERING EXPERIMENT STATION

GRADUATE SCHOOL

SCHOOL OF JOURNALISM

SCHOOL OF LAW

SCHOOL OF MEDICINE

SCHOOL OF NURSING

UNIVERSITY EXTENSION DIVISION

SCHOOL OF VeTERINARY MEDICINE

For the Division at Rolla:

SCHOOl of Mines ANd Metallurgy 
University of Missouri Libraries

University of Missouri

MU Engineering Experiment Station Series

Local Identifier

Pittman1964

Capture information

Date captured 2018 January

Scanner manufacturer Ricoh

Scanner model MP C4503

Scanning software

optical resolution

Color settings

600 dpi

File types

Grayscale, 8 bit; Color 24 bit

Tiff

Source information

Format

Book

Content type

Text

Notes

Digitized duplicate copy not retained in collection.

Derivatives - Access copy

Compression

Editing software

Resolution

Color

File types

Notes

\section{$\mathrm{LZW}$}

Adobe Photoshop

600 dpi

Grayscale, 8 bit; Color, 24 bit

Tiffs converted to pdf

Greyscale pages cropped and canvassed. Noise removed from background and text darkened.

Color pages cropped. 